\title{
Prevalence of Metabolic Syndrome in Saudi Population
}

\author{
Khalid S Aljabri*, Samia A Bokhari, Muneera A Alshareef and Patan M Khan \\ * Department of Endocrinology, King Fahad Armed Forces Hospital, Saudi Arabia
}

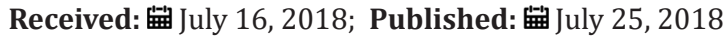

*Corresponding author: Khalid SJ Aljabri, Department of Endocrinology, King Fahad Armed Forces Hospital, Jeddah, Kingdom of Saudi Arabia, PO Box 9862, Jeddah 21159, Kingdom of Saudi Arabia

\section{Abstract}

Background and Objective: Metabolic syndrome (MetS) is a cluster of metabolic factors. The prevalence of MetS are increasing worldwide. The aim of this study was to determine the prevalence as well as the individual components of MetS in Saudi population.

Methods: We analyzed 2810 participants who are equal to or older than 18 years old. All cases were from the population of the primary health at King Fahad Armed Forces Hospital. All data were collected by personal interview and based on a review of electronic medical records. Physician and nurse interviewers measured and recorded weight $(\mathrm{kg})$ and height (cm). Metabolic risk factors were defined using the 2006 International Diabetes Federation criteria that define elevated triglyceride (TG) as $\geq 150$ $\mathrm{mg} / \mathrm{dL}(\geq 1.7 \mathrm{mmol} / \mathrm{L})$ and reduced HDL as $<40 \mathrm{mg} / \mathrm{dL}(<1.03 \mathrm{mmol} / \mathrm{L})$ for male and as $<50 \mathrm{mg} / \mathrm{dL}(<1.29 \mathrm{mmol} / \mathrm{L})$ for female. Hypertension (HTN) was defined when the systolic blood pressure was $\geq 130 \mathrm{~mm} \mathrm{Hg}$ and/or diastolic blood pressure was $\geq 85 \mathrm{~mm}$ $\mathrm{Hg}$ in addition to receiving any medication for HTN. Abnormal glucose metabolism was con $\neg$ sidered when HbA1c ( 25.7$)$ or when patients were known to have type 2 diabetes (T2DM). A combination of two or more of these risk factors was used to assess cutoff values for BMI. Body mass index (BMI) values classified as lean (BMI $<18.5$ ), normal weight (BMI=18.5-24.9 kg/m²), overweight $\left(B M I=25.0-29.9 \mathrm{~kg} / \mathrm{m}^{2}\right)$, obese $\left(B M I \geq 30 \mathrm{~kg} / \mathrm{m}^{2}\right.$. The total number of females were separated on basis of age values into 5 groups: $<30$ years, $30-39$ years, $40-49$ years, $50-59$ years and $\geq 60$ years.

Main results: Of the 2810 participants analyzed, 1060 (37.7\%) were male and 1750 (62.3\%) were female with female to male ratio 1.7:1. Age was 42.7 \pm 15.8 (minimum 18 years and maximum 105 years). MetS was present in 1815 cases (64.4\%) where 692 cases $(38.1 \%)$ were male and 1123 cases $(61.9 \%)$ were female with female to male ratio 1.6:1, $\mathrm{P}=0.6$. Males were significantly older than females in MetS patients ( $56.4 \pm 12.9$ vs. $53.6 \pm 12.4$ respectively, $\mathrm{p}<0.0001$ ). BMI was significantly higher in females than males with MetS patients $(33.0 \pm 7.2$ vs. $30.1 \pm 5.0$ respectively, $\mathrm{p}<0.0001)$. Female patients with metabolic syndrome were significantly younger, had higher except TG mean BMI and HbA1c $>5.6$ or Type 2 diabetes mellitus. Patients with T2DM or having HbA1c $>5.6$ were 3-fold to possess MetS $(\mathrm{OR}=3.3$; 95\% confidence interval $[\mathrm{CI}]=3.0,3.8$, or had been diagnosed with $\mathrm{HTN}(\mathrm{OR}=2.1$; $95 \% \mathrm{CI}=2.0$, 2.2), ( $\mathrm{p}<0.0001)$, have low levels of HDL-cholesterol $(\mathrm{OR}=3.6 ; 95 \% \mathrm{CI}=2.7,4.9)$ and were also more likely to have elevated plasma triglyceride levels $(\mathrm{OR}=1.9 ; 95 \% \mathrm{CI}=1.8,2.0)$. MetS prevalence is consistently statistically significant with increasing age $(\mathrm{p}<0.0001)$. Moreover, the frequency of MetS is consistently statistically significant with increasing BMI $(\mathrm{p}<0.0001)$ and higher among older age group $\geq 60$ years of age in all patients and both genders. Moreover, MetS prevalence was higher among BMI $\geq 30$ group in all patients and both genders. Thus, the mean of BMI among MetS is statistically significant correlated with increasing with advanced age, $(\mathrm{r}=$ $-0.1, \mathrm{p}<0.0001)$.

Conclusion: The prevalence of metabolic syndrome among Saudis is relatively high. Female gender, old age and obesity can be regarded as related factors.

Keywords: Metabolic syndrome; Prevalence

Abbreviations: HDL: Low High-Density Lipoprotein; HTN: Hypertension; TG: Triglycerides; WHO: World Health Organization; NCEP: National Cholesterol Education Program; ATP III: Adult Treatment Panel III; IDF: International Diabetes Federation; CVD: Cardiovascular Disease; T2DM: Type 2 Diabetes Mellitus. 


\section{Introduction}

Metabolic syndrome (MetS) is a cluster of metabolic factors. MetS was initially observed in 1923 by Kyln, who described the clustering of hypertension, hyper glycaemia and gout as the syndrome [1]. Subsequently, several other metabolic abnormalities have been associated with this syndrome, including obesity, microalbuminuria, and abnormalities in fibrinolysis and coagulation [2]. In 1988, Gerald Reaven reintroduced the concept of Syndrome X for the clustering of cardiovascular risk factors like hypertension (HTN), glucose intolerance, high triglycerides (TG) and low high density lipoprotein (HDL) concentration [3]. The first official definition of MetS put forward by a working group of the World Health Organization (WHO) in 1999, a number of different definitions have been proposed. There have been several definitions of MS, but the most commonly used criteria for definition at present are from the National Cholesterol Education Program (NCEP) Adult Treatment Panel III (ATP III), the International Diabetes Federation (IDF), and the World Health Organization (WHO). [4-9]. Risk factor clustering in the MetS cannot be explained by chance alone [10].

Therefore, the syndrome is widely accepted as an important risk factor for cardiovascular disease (CVD) morbidity and mortality and type 2 diabetes mellitus (T2DM) [4,11-14]. MetS increases the risk of developing T2DM by three to five-fold and CVD by twofold, and it has become a major public health challenge around the world $[7,15,16]$. As the various abnormalities of MetS may be documented up to 10 years before the detection of T2DM or CVD, there is a potential to prevent both of them in persons identified with MetS [9]. The purpose of identifying people with the MetS is to reduce the long term risk of developing T2DM, CVD, other forms of atherosclerotic disease, chronic renal disease, obstructive sleep apnea, nonalcoholic fatty liver disease, and gout [17]. However, the estimated prevalence of MetS differs between various populations, because variations exist in the frequencies of metabolic risk components [18]. The MetS has gained a great interest worldwide because of its increasing prevalence [9].

MetS affects around 20\%-25\% of the world population and its prevalence has been globally increased, because of Westernization of lifestyle with less physical activity and increased obesity [16,1921]. Al-Nozha and colleagues previously reported that MetS was almost $40 \%$ among adults in a kingdom-wide sample population taken from 1995-2000 [22]. Since then, other epidemiologic studies conducted within the Arab Peninsula confirmed the same high prevalence [23-25]. The prevalence of MetS varies widely between populations from $8 \%$ to $43 \%$ in men and from $7 \%$ to $56 \%$ in women around the world [19]. Genetic background, socioeconomic status, diet, and lifestyle influence the prevalence of the MetS and its components [19]. The differences in prevalence of MetS depend on population characteristics (such as ethnicity, age and sex), geographic location, and the criteria used for the definition [26-28]. Despite the prevalence of MetS is well known in various populations, there is no in-depth information available about the prevalence of MetS and the individual components within particular combined subgroups of sex, BMI and age. However, recent studies on the clustering of the metabolic risk factors in the form of MetS in Saudi population are limited. Therefore, the aim of this study was to determine the prevalence as well as the individual components of MetS in Saudi population.

\section{Methods}

We analyzed 2810 participants who are equal to or older than 18 years old. All cases were from the population of the primary health at King Fahad Armed Forces Hospital. All data were collected by personal interview and on the basis of a review of electronic medical records. Physician and nurse interviewers measured and recorded weight $(\mathrm{kg})$ and height $(\mathrm{cm})$. Metabolic risk factors were defined using the 2006 IDF criteria that define elevated triglyceride as $\geq 150 \mathrm{mg} / \mathrm{dL}(\geq 1.7 \mathrm{mmol} / \mathrm{L}$ ) and reduced HDL as $<40 \mathrm{mg} / \mathrm{dL}$ $(<1.03 \mathrm{mmol} / \mathrm{L})$ for male and as $<50 \mathrm{mg} / \mathrm{dL}(<1.29 \mathrm{mmol} / \mathrm{L})$ for female [29]. HTN was defined when the systolic blood pressure was $\geq 130 \mathrm{~mm} \mathrm{Hg}$ and/or diastolic blood pressure was $\geq 85 \mathrm{~mm} \mathrm{Hg}$ in addition to receiving any medication for hypertension. Abnormal glucose metabolism was con $\neg$ sidered when HbA1c ( $\geq 5.7$ ) or when patients were known to have type 2 diabetes. A combination of two or more of these risk factors was used to assess cutoff values for BMI. Body mass index (BMI) values classified into groups as lean (BMI<18.5), normal weight $\left(\mathrm{BMI}=18.5-24.9 \mathrm{~kg} / \mathrm{m}^{2}\right)$, overweight $\left(B M I=25.0-29.9 \mathrm{~kg} / \mathrm{m}^{2}\right)$, obese $\left(B M I \geq 30 \mathrm{~kg} / \mathrm{m}^{2}\right.$ [30]. The total number of females were separated on basis of age values into 5 groups: $<30$ years, 30-39 years, 40-49 years, 50-59 years and $\geq 60$ years.

\section{Statistical Analysis}

Unpaired t-test analysis and Chi square $\left(\mathrm{X}^{2}\right)$ test (categorical data comparison) were used between variables to estimate the significance of different between groups for demographic and clinical laboratory. The independent relationship between the stratified BMI and the odds ratio of having MetS were analysed using Chi square $\left(\mathrm{X}^{2}\right)$. All statistical analyses were performed using SPSS Version 22.0. The difference between groups was considered significant when $\mathrm{P}<0.05$.

\section{Results}

Of the 2810 participants analyzed, 1060 (37.7\%) were male and $1750(62.3 \%)$ were female with female to male ratio 1.7:1. Age was 42.7 \pm 15.8 (minimum 18 years and maximum 105 years), (Table 1). MetS was present in 1815 cases (64.4\%) where 692 cases (38.1\%) were male and 1123 cases (61.9\%) were female with female to male ratio 1.6:1, $\mathrm{P}=0.6$, (Table 2). Males were significantly older than females in MetS patients $(56.4 \pm 12.9$ vs. 53.6 \pm 12.4 respectively, $\mathrm{p}<0.0001)$. BMI was significantly higher in females than males with MetS patients (33.0 \pm 7.2 vs. $30.1 \pm 5.0$ respectively, $\mathrm{p}<0.0001$ ). Female patients with metabolic syndrome were significantly younger, had higher except TG mean BMI and HbA1c $>5.6$ or Type 
2 diabetes mellitus (Table 3). shows patients with T2DM or having HbA1c $>5.6$ were 3 -fold to possess MetS $(\mathrm{OR}=3.3$; 95\% confidence interval $[\mathrm{CI}]=3.0,3.8$, or had been diagnosed with HTN $(\mathrm{OR}=2.1$; $95 \% \mathrm{CI}=2.0,2.2),(\mathrm{p}<0.0001)$, have low levels of HDL-cholesterol $(\mathrm{OR}=3.6 ; 95 \% \mathrm{CI}=2.7,4.9)$ and were also more likely to have elevated plasma triglyceride levels $(\mathrm{OR}=1.9 ; 95 \% \mathrm{CI}=1.8,2.0)$. MetS prevalence is consistently statistically significant with increasing age $(p<0.0001)$. Moreover, the frequency of MetS is consistently statistically significant with increasing BMI $(p<0.0001)$ and higher among older age group $\geq 60$ years of age in all patients and both genders, (Figure 1A \& C). Moreover, MetS prevalence was higher among $\mathrm{BMI} \geq 30$ group in all patients and both genders, (Figure $1 \mathrm{~B}$ $\&$ D). Thus, the mean of BMI among MetS is statistically significant correlated with increasing with advanced age, $(r=-0.1, p<0.0001)$.
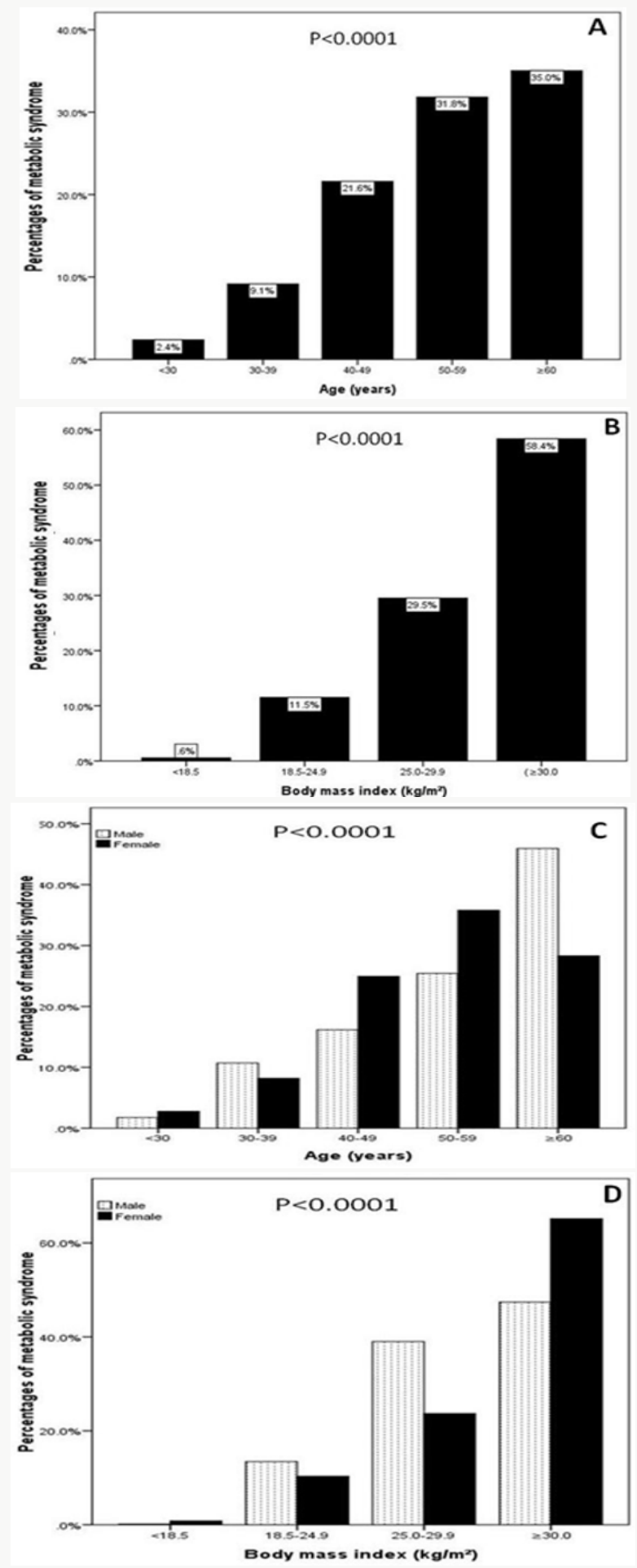

Figure 1: Percentages of women with metabolic syndrome across different age groups $(\mathrm{A})$ and in relation to gender (C) and body mass index ranges (B) and in relation to gender (D). 
Table 1: Basic characteristics of the population under study (means \pm SD or number $(\%)$ )

\begin{tabular}{|c|c|c|}
\hline \multicolumn{2}{|c|}{ Parameters } & Total \\
\hline \multicolumn{2}{|c|}{$\mathrm{n}(\%)$} & 2810 \\
\hline \multicolumn{2}{|c|}{ Age (years) } & $51.3 \pm 15.6$ \\
\hline \multirow{2}{*}{ Gender } & Male & $1060(37.7)$ \\
\hline & Female & $1750(62.3)$ \\
\hline \multicolumn{2}{|c|}{ Body mass index $\left(\mathrm{kg} / \mathrm{m}^{2}\right)$} & $31.3 \pm 6.7$ \\
\hline \multicolumn{2}{|c|}{ HbA1c $>5.6$ or Type 2 diabetes mellitus } & $1949(69.4)$ \\
\hline \multicolumn{2}{|c|}{ Hypertension } & $1131(40.2)$ \\
\hline \multicolumn{2}{|c|}{ Triglyceride ( $\geq 1.7 \mathrm{mmol} / \mathrm{l})$} & $964(34.3)$ \\
\hline \multicolumn{2}{|c|}{ High density lipoprotein (<1.29 mmol/l) } & $1473(52.4)$ \\
\hline \multicolumn{2}{|c|}{ Parameters } & Total \\
\hline \multicolumn{2}{|c|}{ n (\%) } & 2810 \\
\hline \multicolumn{2}{|c|}{ Age (years) } & $51.3 \pm 15.6$ \\
\hline \multicolumn{2}{|c|}{ Body mass index $\left(\mathrm{kg} / \mathrm{m}^{2}\right)$} & $31.3 \pm 6.7$ \\
\hline \multicolumn{2}{|c|}{ HbA1c $>5.6$ or Type 2 diabetes mellitus } & $1949(69.4)$ \\
\hline \multicolumn{2}{|c|}{ Hypertension } & $1131(40.2)$ \\
\hline \multicolumn{2}{|c|}{ Triglyceride $(\geq 1.7 \mathrm{mmol} / \mathrm{l})$} & $964(34.3)$ \\
\hline \multicolumn{2}{|c|}{ High density lipoprotein (<1.29 mmol/l) } & $1473(52.4)$ \\
\hline
\end{tabular}

Table 2: Characteristics of the population with metabolic syndrome under study stratified by gender (means \pm SD or number $(\%)$ ).

\begin{tabular}{|c|c|c|c|c|}
\hline \multirow{2}{*}{ Parameters } & \multirow{2}{*}{ Total } & \multicolumn{2}{|c|}{ Gender } & \multirow{2}{*}{ P value } \\
\cline { 2 - 4 } & & Male & Female & \multirow{2}{*}{0.6} \\
\hline $\mathrm{n}(\%)$ & $1815(64.6)$ & $692(38.1)$ & $53.6 \pm 2.4$ & $<0.0001$ \\
\hline Age $($ years $)$ & $54.7 \pm 12.6$ & $56.4 \pm 2.9$ & $33.0 \pm 7.2$ & $<0.0001$ \\
\hline Body mass index $\left(\mathrm{kg} / \mathrm{m}^{2}\right)$ & $31.9 \pm 6.6$ & $30.1 \pm 5.0$ & $1010(89.9)$ & 0.006 \\
\hline HbA1c $>5.6$ or Type 2 diabetes mellitus & $1603(88.3)$ & $593(85.7)$ & $666(59.3)$ & 0.6 \\
\hline Hypertension & $1067(58.8)$ & $401(57.9)$ & $497(44.3)$ & $<0.0001$ \\
\hline High densiglyceride $(\geq 1.7 \mathrm{mmol} / \mathrm{l})$ & $905(49.9)$ & $408(59.0)$ & $804(71.6)$ & 0.07 \\
\hline
\end{tabular}

Table 3: The risk of metabolic syndrome phenotype among metabolic syndrome.

\begin{tabular}{|c|c|c|c|c|}
\hline \multirow{2}{*}{ Parameters } & \multirow{2}{*}{ Total } & \multicolumn{2}{|c|}{ Gender } & \multirow{2}{*}{ P value } \\
\cline { 2 - 5 } & & Male & Female & \multirow{2}{*}{0.6} \\
\hline $\mathrm{n}(\%)$ & $1815(64.6)$ & $692(38.1)$ & $1123(61.9)$ & $<0.0001$ \\
\hline Age $($ years $)$ & $54.7 \pm 12.6$ & $56.4 \pm 12.9$ & $53.6 \pm 12.4$ & $<0.0001$ \\
\hline Body mass index $\left(\mathrm{kg} / \mathrm{m}^{2}\right)$ & $31.9 \pm 6.6$ & $30.1 \pm 5.0$ & $33.0 \pm 7.2$ & 0.006 \\
\hline HbA1c $>5.6$ or Type 2 diabetes mellitus & $1603(88.3)$ & $593(85.7)$ & $1010(89.9)$ & 0.6 \\
\hline Hypertension & $1067(58.8)$ & $401(57.9)$ & $666(59.3)$ & $<0.0001$ \\
\hline Triglyceride $(\geq 1.7 \mathrm{mmol} / \mathrm{l})$ & $905(49.9)$ & $408(59.0)$ & $497(44.3)$ & 0.07 \\
\hline
\end{tabular}

\section{Discussion}

Proper definition of the causes and risk factors of MetS is mandatory for prevention and/or treatment of MetS. In addition to the well-defined risk factors for MetS, there are diseases and conditions that lead to MetS secondarily (Table 4). Knowing these conditions and defining them as risk factors is of importance in the approach toward patients with MetS. In the present study, in which we aimed to determine the factors that would lead to secondary MetS, the characteristics of 2810 patients with MetS were evaluated. Considering the IDF criteria for MetS diagnosis, we showed that around $64.6 \%$ of the cohort analyzed presented the syndrome, which was more prevalent in female's individuals $(61.9 \%, p=0.6)$. Noticeably higher than the estimated global prevalence, which is between 20 and $25 \%$ and finding is higher than other national and regional studies $[6,22,24,25]$. 
Table 4: Numbers (\%) of metabolic syndrome according to $\mathrm{HbA} 1 \mathrm{c}>5.6$ or Type 2 diabetes mellitus, hypertension, Triglyceride $(\geq 1.7 \mathrm{mmol} / \mathrm{l})$ and High-density lipoprotein $(<1.29$ $\mathrm{mmol} / \mathrm{l}$ ) across different age groups.

\begin{tabular}{|c|c|c|c|c|}
\hline $\begin{array}{c}\text { Age } \\
\text { (years) }\end{array}$ & $\begin{array}{c}\text { HbA1c>5.6 } \\
\text { or Type 2 } \\
\text { diabetes } \\
\text { mellitus }\end{array}$ & Hypertension & $\begin{array}{c}\text { Triglyceride } \\
\mathbf{2} \mathbf{1 . 7} \\
\mathbf{m m o l} / \mathbf{l})\end{array}$ & $\begin{array}{c}\text { High } \\
\text { density } \\
\text { lipoprotein } \\
\mathbf{( < 1 . 2 9} \\
\mathbf{m m o l} / \mathbf{l})\end{array}$ \\
\hline$<30$ & $33(76.7)$ & $12(27.9)$ & $22(51.2)$ & $35(81.4)$ \\
\hline $30-39$ & $122(73.5)$ & $38(22.9)$ & $109(65.7)$ & $136(81.9)$ \\
\hline $40-49$ & $328(83.7)$ & $150(38.3)$ & $200(51.0)$ & $304(77.6)$ \\
\hline $50-59$ & $525(90.8)$ & $382(66.1)$ & $278(48.1)$ & $399(69.0)$ \\
\hline$\geq 60$ & $595(93.6)$ & $485(76.3)$ & $296(46.5)$ & $398(62.6)$ \\
\hline Total & $1603(88.3)$ & $1067(58.8)$ & $905(49.9)$ & $1272(70.1)$ \\
\hline P value & $<0.0001$ & $<0.0001$ & $<0.0001$ & $<0.0001$ \\
\hline
\end{tabular}

In Saudi Arabia the prevalence of MetS was found to be $39.8 \%$ (34.4\% in men and $29.2 \%$ in women) and 31.6\% (45.0\% in men and $35.4 \%$ in women), according to the NCEP ATP III and IDF criteria, respectively [31-38]. Another national study found the prevalence to be $39.3 \%$ in 2005, using the 2001 ATP III criteria [22]. In the Arab population, the prevalence of MetS also differs between countries. In Lebanon, the overall prevalence of MetS was 31.2\% (38.6\% in men and $25.8 \%$ in women); in Oman, the age adjusted prevalence was $19.5 \%$ among men and $23.0 \%$ among women; in United Arab Emirates, the prevalence rate is over $40 \%$; and in the West Bank, the age-adjusted prevalence of MetS was estimated at only $17 \%$
[31,39-41]. A study conducted in Baghdad in 2011 showed that the prevalence of metabolic syndrome in females was almost double that in males (34.8 versus 65.2\%) [42]. An Indian study revealed that the prevalence of metabolic syndrome was $57.38 \%$ in females and $42.63 \%$ in males, whereas a study in Tunisia revealed that the prevalence was $45.5 \%$, significantly higher among women $[16,43]$.

This indicates that there might be some changes in the risk factors especially among females that can be explained by the fact that females, most of whom are housewives in our society, are more prone to obesity after child birth, besides, women transition from the premenopausal to the postmenopausal stage with substantial metabolic changes and estrogen deficiency might lead to an increased predisposition to metabolic syndrome. The difference in prevalence of MetS between men and women may be related to differences in body fat distribution: men have more visceral and hepatic fat, whereas women have more total body fat. 44 Differences in distribution of fat with age (total fat and visceral fat) and the cardiometabolic effects of menopause may explain the diminished sex difference in MetS prevalence seen with older age $[44,45]$. In females, menopause and estrogen deficiency appears to be independent predisposing factor for the development of most of the components of the MetS $[46,47]$. The current study showed that the prevalence of metabolic syndrome is significantly increasing with age. The age groups 50 to 59 and $\geq 60$ years had the highest frequencies of metabolic syndrome that can be explained by the aging process.

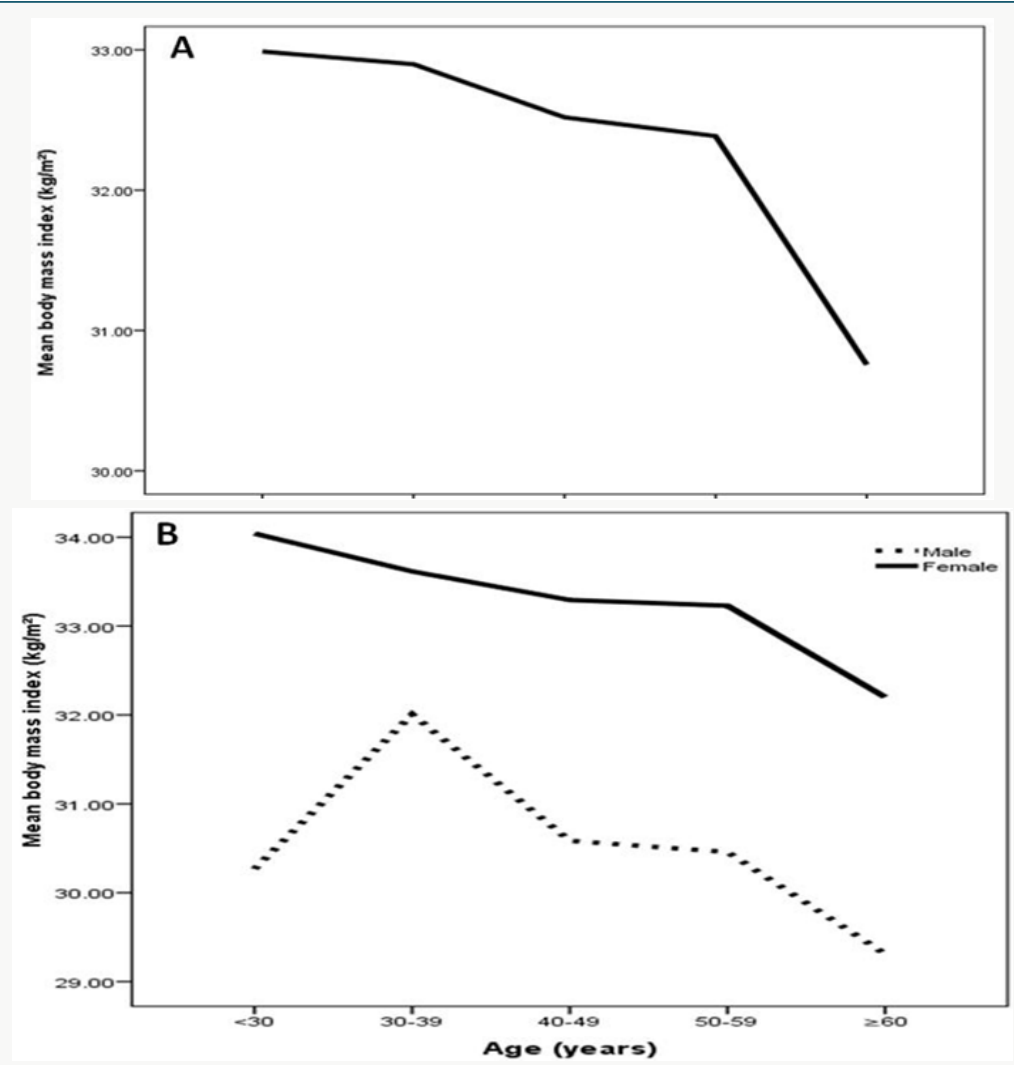

Figure 2: Mean body mass index $\mathrm{kg} / \mathrm{m}^{2}$ in patients with metabolic syndrome across different age groups (A) stratified to gender and in relation to gender $(\mathrm{B})$. 
This is lower than a study done among US adults and showed that the prevalence increases from $11.5 \%$ vs.18.3\% among those 20 to 39 years of age to 35.0 vs. $46.7 \%$ among those 60 years or older (Figure 2). and this is also supported by a study in UAE that showed a positive association between the prevalence of metabolic syndrome and age $[42,48]$. Similar to other observations, we found that the prevalence of MetS increases with age, up to the seventh age decade, and in contrary to others, that it is higher in female than in male [49-53]. Data from NHANES III (1988-1994) showed, however, that prevalence of MetS in women exceeded that of men, when individuals older than 50 years of age were evaluated [53]. In some studies, prevalence estimates for MetS are found to plateau or drop off after the sixth or seventh age decade in both sexes or only in men [54-57]. This observation might be due to a survival effect or participation bias, as individuals prone to obesity-related morbidity and mortality have already died or decline to participate in a study [58]. The observed trend of increasing MetS prevalence with age can be explained by the large number of people developing metabolic complications by the time they are aged $\geq 60$ years (i.e. more than $85 \%$ of the individuals have at least one metabolic risk factor).

Due to the age-related rises of blood pressure, obesity and glucose a more similar make-up of MetS was seen in the elderly, whereas in younger people, the MetS profile was more heterogeneous and differed more by sex. While it may also depend on the definition used for MetS even if the same definition was used, different trends were observed between countries [54,59]. This underpins the importance of estimating the country-specific prevalence of MetS. Obesity is an alarming public health challenge of the $21^{\text {st }}$ century. MetS is one of the associated co-morbidities of obesity [60]. We also observed that MetS were more significant and frequent in individuals with higher BMI values, specifically in obese patients compared to those considered overweight. When analyzing the variables associated with insulin resistance, we found significant differences in female groups for all criteria. A higher percentage of females (89.9\% \%), than males (85.7\%), presented insulin resistance according to $\mathrm{HbA} 1 \mathrm{c}>5.6$ or $\mathrm{T} 2 \mathrm{DM}$ values. $\mathrm{HbA1}>5.6$ or T2DM was the most frequent of the cardiometabolic parameters, followed by abnormal blood pressure, low HDL and high triglycerides levels.

This is in agreement with study from Iraq who showed diabetes mellitus followed by hypertriglyceridemia and hypertension; and disagrees with national study showed the most frequently observed component of metabolic syndrome was found to be low levels of HDL and the Indian study, which showed that the main component was hypertension (98.37\%), followed by dyslipidemia (77.05\%), hyperglycemia (75.41\%), and obesity $(59.02 \%)[16,38]$. This disagreement might be due to differences in population characteristics or in the research methodology. When MetS were analyzed in groups stratified by gender, we observed an increased prevalence in females. Approximately $89.9 \%$ of females had HbA1c $>5.6$ or T2DM followed by low HDL levels $71.6 \%$ and $59.3 \%$ had increased HTN. In males, HbA1c>5.6 or T2DM was the most frequent $(85.7 \%)$ altered cardiometabolic parameter, followed by low HDL levels (67.6\%), and 59.0\% had increased TG. In young female, we found that a large proportion had HbA1c>5.6 or T2DM, namely $77.4 \%$ vs. 75.0 for male respectively, below the age of 30 years. This finding may suggest that, across the entire lifespan, HbA1c $>5.6$ or T2DM has a greater relative importance in the development of MetS in female than in male. Regardless of gender, the obese group presented the highest degree of insulin resistance. We found that there is heterogeneity in the metabolic risk status of individuals with normal weight, overweight, or obesity. We observed in our hospital-based sample that $50 \%$ of men and women with normal weight who had MetS in consistence with others and modest numbers with obesity (30.5\%) but without MetS. [61-68]. Hypertriglyceridemia was present in $49.9 \%$ of the sample; this is similar to a study that was carried out among Iraqi adult population (2003-2004),

which revealed that the prevalence of hypertriglyceridemia was 41.6\% [69]. Reports from neighboring Middle Eastern countries vary from $40.3 \%$ in Saudi Arabia to $35.3 \%$ in Lebanon, $30.4 \%$ in Turkey, and $20.7 \%$ in Oman. [70]. In the current study, $70.1 \%$ of the sample showed low HDL; this is higher than a study done in Iraq and showed a prevalence of 49.9 and is lower than that in Oman which showed a low HDL in $75.4 \%[31,42]$. MetS is an asymptomatic, pathophysiological state characterized by obesity, insulin resistance, hypertension, dysglycaemia, and dyslipidemia. The clinical utility of MetS has been criticized for quit some years $[71,72]$. Criticism is related to the predictive value of MetS for CVD. MetS is found to have no greater predictive value for CVD compared to the individual components [73]. Furthermore, all MetS components are weighted equally while it is clear that some risk factors are more important for risk prediction. Also, continuous variables are dichotomized and MetS is operationalized as a combination of three or more of the five components, which results in a loss of predictive power [74]. In the current ATPIII definition, only blood pressure and fasting glucose are used for targeted risk factor interventions in clinical practice. Though, interventions are seldom started at the levels proposed by the ATPIII [75].

\section{Strengths and Limitations}

One of the strength of our study, the large number of participants allowed us to explore trends within detailed clusters of sex, BMI and age, which has not been done before. Our results should be interpreted in light of the study's limitations. First, most of the patients enrolled were already on treatment for hypertension, diabetes and hypertriglyceridemia, which imposed some limitations on the study. We tried to overcome these by obtaining the necessary sample size and by using data documented before treatment. Finally, as this was a hospital-based, retrospective study, the findings do not represent the whole Saudi population or the local community. Further larger population-based studies are necessary to support our findings. Another limitation of the present study was having considered only overall obesity (assessed by BMI) 
and not abdominal obesity (measured by waist circumference), which is known to bear a close relationship with the target diseases.

\section{Conclusion}

It can be concluded from this study that the prevalence of metabolic syndrome among Saudis is relatively high. Female gender, old age and obesity can be regarded as related factors.

\section{Acknowledgment}

We are grateful to the staffs from the Primary care department at King Fahad Armed Forces Hospital for their valuable contributions in data collection. The authors have no conflict of interest to disclose.

\section{References}

1. Kylin E (1923) Studies on Hypertension Hyperglycemia Hyperuricemia Syndrome. Central Journal for Internal Medicine 44: 105-127.

2. Isomaa B, Almgren P, Tuomi T, Forsen B, Lahti K, et al. (2001) Cardiovascular morbidity and mortality associated with the metabolic syndrome. Diabetes Care 24(4): 683-689.

3. Reaven GM (1988) Banting Lecture 1988. Role of insulin resistance in human disease. Diabetes 37(12): 1595-1607.

4. National Cholesterol Education Program (NCEP) Expert Panel on Detection, Evaluation, and Treatment of High Blood Cholesterol in Adults (Adult Treatment Panel III) (2002) Third Report of the National Cholesterol Education Program (NCEP) Expert Panel on Detection, Evaluation, and Treatment of High Blood Cholesterol in Adults (Adult Treatment Panel III) final report. Circulation 106(25): 3143-3421.

5. Tan BT, Kantilal HK, Singh R (2008) Prevalence of metabolic syndrome among Malaysians using the International Diabetes Federation, National Cholesterol Education Program and Modified World Health Organisation Definitions. Mal J Nutr 14(1): 65-77.

6. (2006) International Diabetes Federation: The IDF Consensus Worldwide Definition of the MS.

7. Zimmet P, Maglian D, Matsuzawa Y, Alberti G, Shaw J (2005) The metabolic syndrome: a global public health problem and a new definition. J Atherosclera Thromb 12(6): 259-300.

8. Alberti KG, Zimmet PZ (1998) Definition, diagnosis and classification of diabetes mellitus and its complications. Part 1: Diagnosis and classification of diabetes mellitus provisional report of a WHO consultation. Diabet Med 15(7): 539-553.

9. WHO (World Health Organization) (1999) Definition, Diagnosis and Classification of Diabetes Mellitus and its Complications. Report of a WHO Consultation. Part 1: Diagnosis and Classification of Diabetes Mellitus. Department of Non-communicable Disease Surveillance. Geneva, Switzerland.

10. Grundy S (2006) Does a diagnosis of metabolic syndrome have value in clinical practice? Am J Clin Nutr 83(6): 1248-1251.

11. Liberopoulos EN, Mikhalidis DP, Elisaf MS (2005) Diagnosis and management of the metabolic syndrome in obesity. Obes Rev 6(4): 283296.

12. Bener A, Mohammad AG, Ismail AN, Zirie M, Abdullatef WK, et al. (2010) Gender and age-related differences in patients with the metabolic syndrome in a highly endogamous population," Bosnian Journal of Basic Medical Sciences 10(3): 210-217.

13. Moller DE, Kaufman KD (2005) Metabolic syndrome: a clinical and molecular perspective. Annual Review of Medicine 56: 45-62.
14. Scott CL (2003) Diagnosis, prevention and intervention for the metabolic syndrome. American Journal of Cardiology 92(1A): 35i-42i.

15. Alberti KG, Eckel RH, Grundy SM, Zimmet PZ, Cleeman JI, et al. (2009) Harmonizing the metabolic syndrome: A joint interim statement of the international diabetes federation task force on epidemiology and prevention; national heart, lung, and blood institute; american heart association; world heart federation; international atherosclerosis society; and international association for the study of obesity. Circulation 120(16): 1640-1645.

16. Kaur JA (2014) comprehensive review on metabolic syndrome. Cardiol Res Pract 2014: 943162.

17. Petrucelli 0 (2008) The Metabolic Syndrome. Northeast Florida Medicine 59(4): 18-21.

18. Scuteri A, Laurent S, Cucca F, Cockcroft J, Cunha PG, et al. (2015) Metabolic syndrome across Europe: different clusters of risk factors. European Journal of Preventive Cardiology 22 (4): 486-491.

19. Cameron AJ, Shaw JE, Zimmet PZ (2004) The metabolic syndrome: Prevalence in worldwide populations. Endocrinol Metab Clin North Am 33(2): 351-375.

20. Haffner S, Taegtmeyer H (2003) Epidemic obesity and the metabolic syndrome. Circulation 108(13): 1541-1545.

21. Shen J, Goyal A, Sperling L (2012) The emerging epidemic of obesity, diabetes, and the metabolic syndrome in China. Cardiol Res Pract 2012: 178675 .

22. Al Nozha M, Al Khadra A, Arafa MR, Al Maatouq MA, Khalil MZ, et al. (2005) Metabolic syndrome in Saudi Arabia. Saudi Med J 26(12): 19181925.

23. Saadi H, Nagelkerke N, Carruthers SG, Benedict S, Abdulkhalek S, et al. (2008) Association of TCF7L2 polymorphism with diabetes mellitus, metabolic syndrome, and markers of beta cell function and insulin resistance in a population-based sample of Emirati subjects. Diabetes Res Clin Pract. 80(3): 392-398.

24. Khader Y, Bateiha A, El Khateeb M, Al Shaikh A, Ajlouni K (2007) High prevalence of the metabolic syndrome among Northern Jordanians. J Diabetes Complications 21(4): 214-219.

25. Harzallah F, Alberti H, Ben Khalifa F (2006) The metabolic syndrome in an Arab population: a first look at the new International Diabetes Federation criteria. Diabet Med 23(4): 441-444.

26. Ervin R (2009) Prevalence of metabolic syndrome among adults 20 years of age and over, by sex, age, race and ethnicity, and body mass index: United States, 2003-2006. National Health Statistics Reports (13): 1-7.

27. Feng Y, Hong X, Li Z, Zhang W, Jin D, et al. (2006) Prevalence of metabolic syndrome and its relation to body composition in a Chinese rural population. Obesity 14(11): 2089-2098.

28. Thom T, Haase N, Rosamond W, Howard VJ, Rumsfeld J, et al. (2006) Heart disease and stroke statistics 2006 update: A report from the American Heart Association Statistics Committee and Stroke Statistics Subcommittee. Circulation 113(6): e85-e151.

29. Alberti KG, Zimmet P, Shaw I (2006) Metabolic syndrome-a new worldwide definition. A consensus statement from the International Diabetes Federation. Diabetic Medicine 23(5): 469-480.

30. Chen YM, Ho SC, Lam SS, Chan SS (2006) Validity of body mass index and waist circumference in the classification of obesity as compared to percent body fat in Chinese middle-aged women. Int J Obes (Lond) 30(6): 918-925.

31. Al Lawati J, Mohammed A, Al Hinai H, Jousilahti P (2003) Prevalence of the Metabolic Syndrome Among Omani Adults. Diabetes Care 26(6):1781-1785. 
32. Alzahrani A, Karawagh A, Alshahrani F, Naser T, Ahmed A, et al. 2012) Prevalence and predictors of metabolic syndrome among healthy Saudi adults. Br J Diabet Vasc Dis 12(2): 78.

33. Al Daghri NM (2010) Extremely high prevalence of metabolic syndrome manifestations among Arab youth: A call for early intervention. Eur J Clin Invest 40(12): 1063-1066.

34. Al Shaibani H, El Batish M, Sorkhou I, Al Shamali N, Al Namash H, et al. (2004) Prevalence of insulin resistance syndrome in a primary health care center in Kuwait. Fam Med 36(8): 540.

35. Kozan 0, Oguz A, Abaci A, Erol C, Ongen Z, et al. (2007) Prevalence of the metabolic syndrome among Turkish adults. Eur J Clin Nutr 61(4): 548-553.

36. Malik M, Razig SA (2008) The prevalence of the metabolic syndrome among the multiethnic population of the United Arab Emirates: A report of a national survey. Metab Syndr Relat Disord 6(3): 177-186.

37. Zabetian A, Hadaegh F, Azizi F (2007) Prevalence of metabolic syndrome in Iranian adult population, concordance between the IDF with the ATPIII and the WHO definitions. Diabetes Res Clin Pract 77(2): 251-257.

38. Khalid Al Rubeaan, Nahla Bawazeer, Yousuf Al Farsi, Amira M Youssef, Abdulrahman A. Al-Yahya, et al. (2018) Prevalence of metabolic syndrome in Saudi Arabia - a cross sectional study BMC Endocrine Disorders 18: 16.

39. Abdul Rahim H, Husseini A, Bjertness E, Giacaman R, Gordon N, et al. (2001) The Metabolic Syndrome in the West Bank population. Diabetes Care 24: 275-279.

40. Sibai A, Obeid O, Batal M, Adra N, El Khoury D, et al. (2008) Prevalence and correlates of metabolic syndrome in an adult Lebanese population. CVD Prev Cont 3(2): 83-90.

41. Al Sarraj T, Saadi H, Calle M, Volek J, Fernandez M (2009) Carbohydrate restriction, as a first-line dietary intervention, effectively reduces biomarkers of Metabolic Syndrome in Emirati adults. J Nutr 139(9): 1667-1676.

42. Al Rubaye FG (2011) Frequency of metabolic syndrome in a sample of adult diabetics in Baghdad. Iraqi J Community Med 24:12-16.

43. Bouguerra R, Alberti H, Smida H, Salem LB, Rayana CB, et al. (2007) Waist circumference cut-off points for identification of abdominal obesity among the Tunisian adult population. Diabetes Obes Metab 9(6): 859-868.

44. Pradhan AD (2014) Sex differences in the metabolic syndrome: implications for cardiovascular health in women. Clinical Chemistry 60(1): 44-52.

45. Rosano GM, Vitale C, Marazzi G, Volterrani M (2007) Menopause and cardiovascular disease: the evidence. Climacteric. 10(1): 19-24.

46. Carr MC (2003) The emergence of the metabolic syndrome with menopause. J Clin Endocrinol Metab 88(6): 2404-2411.

47. Ben Ali S, Belfki Benali H, Aounallah Skhiri H, Traissac P, Maire B, et al. (2014) Menopause and metabolic syndrome in Tunisian women Biomed Res Int 2014: 457131.

48. Aguilar M, Bhuket T, Torres S, Liu B, Wong RJ (2015) Prevalence of the metabolic syndrome in the United States, 2003-2012. JAMA 313(19): 1973-1974.

49. Alkerwi A, Donneau AF, Sauvageot N, Lair ML, Scheen A, Albert A et al. (2011) Prevalence of the metabolic syndrome in Luxembourg according to the Joint Interim Statement definition estimated from the ORISCAVLUX study. BMC Public Health 11(1): 4.

50. Hildrum B, Mykletun A, Hole T, Midthjell K \& Dahl AA (2007) Age-specific prevalence of the metabolic syndrome defined by the International Diabetes Federation and the National Cholesterol Education Program: the Norwegian HUNT 2 study. BMC Public Health. 7: 220.
51. Cornier MA, Dabelea D, Hernandez TL, Lindstrom RC, Steig AJ, et al. (2008) The metabolic syndrome. Endocrine Reviews 29(7): 777-822.

52. Scuteri A, Laurent S, Cucca F, Cockcroft J, Cunha PG, et al. (2015) Metabolic syndrome across Europe: different clusters of risk factors. European Journal of Preventive Cardiology 22(4): 486-491.

53. Ford ES, Giles WH, Dietz WH (2002) Prevalence of the metabolic syndrome among US adults: findings from the third National Health and Nutrition Examination Survey. JAMA 287(3): 356-359.

54. Cameron AJ, Magliano DJ, Zimmet PZ, Welborn T, Shaw JE (2007) The metabolic syndrome in Australia: prevalence using four definitions. Diabetes Research and Clinical Practice. 77(3): 471-478.

55. Deepa M, Farooq S, Datta M, Deepa R, Mohan V (2007) Prevalence of metabolic syndrome using WHO, ATPIII and IDF definitions in Asian Indians: the Chennai Urban Rural Epidemiology Study (CURES- 34). Diabetes/Metabolism Research and Reviews. 23(2): 127-134.

56. Adams RJ, Appleton S, Wilson DH, Taylor AW, Dal Grande E, et al. (2005) Population comparison of two clinical approaches to the metabolic syndrome: implications of the new International Diabetes Federation consensus definition. Diabetes Care 28(11): 2777-2779.

57. Ford ES, Li C, Zhao G (2010) Prevalence and correlates of metabolic syndrome based on a harmonious definition among adults in the US. Journal of Diabetes 2(3): 180-193.

58. Zamboni M, Mazzali G, Zoico E, Harris TB, Meigs JB, et al. (2005) Health consequences of obesity in the elderly: a review of four unresolved questions. International Journal of Obesity 29(9): 1011-1029.

59. Gavrila D, Salmeron D, Egea Caparros JM, Huerta JM, Perez Martinez A, et al. (2011) Prevalence of metabolic syndrome in Murcia Region, a southern European Mediterranean area with low cardiovascular risk and high obesity. BMC Public Health 11: 562.

60. Popkin BM, Gordon Larsen P (1999) The nutrition transition: worldwide obesity dynamics and their determinants. Int J Obes Relat Metab Disord 28(3): S2-9.

61. Ruderman NB, Schneider SH, Bechtold P (1981) The metabolicallyobese normal-weight individual. Am J Clin Nutr 34(8): 1617-1621.

62. Ruderman N, Chisholm D, Pi Sunyer X, Schneider S (1998) The metabolically obese, normal-weight individual revisited. Diabetes 47(5):699-713.

63. Zavaroni I, Bonora E, Pagliara M, Dall Aglio E, Luchetti L, et al. (1989) Risk factors for coronary artery disease in healthy persons with hyperinsulinemia and normal glucose tolerance. N Engl J Med 320(11): 702-706.

64. Dvorak RV, DeNino WF, Ades PA, Poehlman ET (1999) Phenotypic characteristics associated with insulin resistance in metabolically obese but normalweight young women. Diabetes 48(11): 2210-2214.

65. St Onge MP, Janssen I, Hempfield SB (2004) Metabolic syndrome in normalweight Americans: new definition of the metabolically obese, normal-weight individual. Diabetes Care 27(9): 2222-2228.

66. Ferrandine E, Natali A, Bell P, Cavallo-Perin P, Lalic N, et al. (1997) Insulin resistance and hypersecretion in obesity. European Group for the Study of Insulin Resistance (EGIR). J Clin Invest 100(5): 1166-1173.

67. Bonora E, Kiechl S, Willeit J, Oberhollenzer F, Egger G, et al. (1998) Prevalence of insulin resistance in metabolic disorders. Diabetes 47(10): $1643-1649$

68. Brochu M, Tchernof A, Dionne IJ, Sites CK, Eltabbakh GH, et al. (2001) What are the physical characteristics associated with a normal metabolic profile despite a high level of obesity in postmenopausal women? J Clin Endocrinol Metab 86(3): 1020-1025.

69. Mula Abed WA, Chilmeran SK (2007) Prevalence of dyslipidemia in the Iraqi adult population. Saudi Med J 28(12): 1868-1874. 
70. Abatabaei Malazy O, Qorbani M, Samavat T, Sharifi F, Larijani B, et al. (2014) Prevalence of dyslipidemia in Iran. Int J Prev Med 5(4): 373-393.

71. Kahn R, Buse J, Ferrannini E, Stern M (2005) The metabolic syndrome: time for a critical appraisal. Joint statement from the American Diabetes Association and the European Association for the Study of Diabetes. Diabetologia 28(9): 1684-1699.

72. Reaven GM (2006) The metabolic syndrome: is this diagnosis necessary? American Journal of Clinical Nutrition 83(6): 1237-1247.

73. Ding EL, Smit LA \& Hu FB (2010) The metabolic syndrome as a cluster of risk factors: is the whole greater than the sum of its parts?: comment on
'The metabolic syndrome, its component risk factors, and progression of coronary atherosclerosis'. Archives of Internal Medicine 170(5): 484485 .

74. Royston P, Altman DG, Sauerbrei W (2006) Dichotomizing continuous predictors in multiple regression: a bad idea. Statistics in Medicine 25(1): 127-141.

75. Sliem HA, Ahmed S, Nemr N, El Sherif I (2012) Metabolic syndrome in the middle east. Indian J Endocrinol Metab 16(1): 67-71.

\section{(C) \\ This work is licensed under Creative Commons Attribution 4.0 License}

To Submit Your Article Click Here:

Submit Article
DOI: $10.32474 / A D 0.2018 .01 .000112$

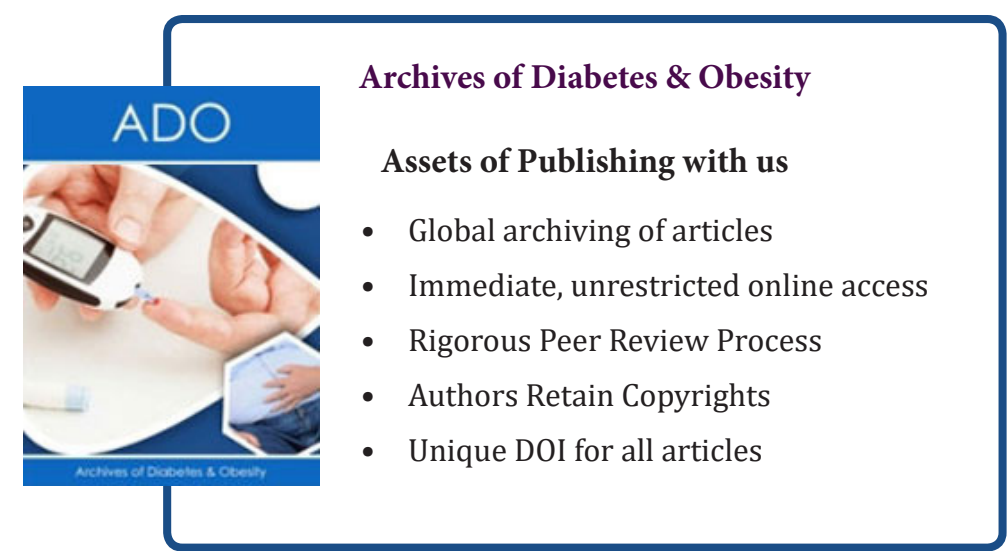

